\title{
Desafios de uma educação plurilinguística em um país que se diz monolíngue: um estudo de caso
}

\author{
Cristiane Horst ${ }^{1}$ \\ Marcelo Jacó Krug ${ }^{2}$ \\ Programa de Pós-graduação em Estudos Linguísticos, Universidade Federal da Fronteira Sul (UFFS), \\ Chapecó, Santa Catarina, Brasil
}

Resumo: Apresentamos, no presente artigo, uma discussão acerca do ser bilíngue desde a infância e dos desafios encontrados, que precisam ser enfrentados e superados, para que a família não desista do seu propósito, principalmente, quando se trata de uma língua de imigração (Deitsch/Deutsch) e o alemão (padrão) em contato com a língua portuguesa. Trazemos uma discussão teórica baseada nas características do bilíngue a partir de Mackey (1972), King e Mackey (2007) e Grosjean (2010) e nos tipos de bilinguismo infantil de Romaine (1995). Dentre os desafios que podem ser encontrados numa educação plurilinguística (BROCH, 2014), destacamos três: i) o mito de que crianças, que aprendem mais de uma língua precocemente, terão dificuldades na escola; ii) o preconceito linguístico, fruto de educação centrada na crença da necessidade de uma homogeneidade linguística e iii) a falta de uma política linguística sensível ao plurilinguismo, tanto de línguas minoritárias, quanto de línguas chamadas "modernas".

Palavras-chave: Bilinguismo/plurilinguismo infantil; Educação plurilinguística; Preconceito linguístico.

Title: Challenges of a multilingual education in a country that claims to be monolingual: a case study Abstract: In this paper, we present a discussion about being bilingual/multilingual since childhood and the challenges encountered, which need to be faced and overcome, so that the family does not give up on its purpose, mainly when it comes to a language of immigration (Deitsch/Deutsch) and the German in contact with the Portuguese. We bring a theoretical discussion based on the features of bilingual/multilingual from Mackey (1972), King and Mackey (2007) and Grosjean (2010) and on the types of child bilingualism by Romaine (1995). Among the challenges that can be found in a multilingual education (BROCH, 2014), we emphasize three of them: i) the myth that children, who learn more than one language prematurely, will have difficulties in school; ii) linguistic prejudice, the result of an education centered on the belief in the need for linguistic homogeneity and iii) the lack of a linguistic policy sensitive to multilingualism, both of minority languages and of languages called "modern".

Keywords: Child bilingualism/multilingualism; Multilingual education; Linguistic prejudice.

\footnotetext{
${ }^{1}$ Doutora em Letras/Filologia Românica pela Christian-Albrechts-Universität zu Kiel, Alemanha. Professora na UFFS. Orcid: http://orcid.org/0000-0003-2782-9903. E-mail: cristianehorst79@gmail.com.

2 Doutor em Letras/Filologia Românica pela Christian-Albrechts-Universität zu Kiel, Alemanha. Professor Associado na UFFS. Orcid: http://orcid.org/0000-0003-2374-0100. E-mail: marcelokrug@uffs.edu.br.
} 


\section{Palavras introdutórias}

Vivemos num cenário de grandes desafios no que se refere ao bilinguismo/plurilinguismo e, principalmente, no que compete ao ensino e à aprendizagem de mais de uma língua na família, em termos de valorização, prestígio e estigma. O mito de que uma criança bilíngue terá dificuldades no aprendizado da língua oficial da escola, continua muito forte. Podemos dizer que a falta de informação e o desinteresse sobre esse tema atinge grande parte da sociedade brasileira, incluindo profissionais da educação, o que faz alimentar tal mito.

Autores como Altenhofen (2004) e Jungblut (2011) descrevem que grande parte do desinteresse e do mito ainda tem relação com a proibição das variedades linguísticas de imigração na época da ditadura militar no Brasil. Época em que a ordem era "um povo, uma língua", colocando o português, como língua única no Brasil. No que diz respeito à língua estrangeira, apenas o inglês era permitido nos currículos escolares (CAMPOS, 2006). É lamentável e inaceitável que hoje, em pleno século XXI, ainda haja preconceito em relação ao ser bilíngue no Brasil e que esse preconceito possa ser um resquício do que nossos antepassados viveram em tempos de ditadura. Outro ponto que merece destaque e que faz com que muitos deixem de falar a variedade de imigração é a questão da estigmatização dessas línguas não dominantes em comparação com a língua majoritária dominante.

Nossos objetivos neste artigo são: i) apresentar um tipo 7 de educação bilíngue/plurilinguística que se adequa a nossa realidade do Oeste Catarinense, a partir dos aspectos teóricos do bilinguismo infantil de Romaine (1995) e da compreensão das características do bilíngue como descrito por Mackey (1972); ii) descrever e analisar a experiência de educação plurilinguística vivida com nossos dois filhos, ambos bilíngues/plurilíngues alemão-português, que passam a estudar em uma escola monolíngue em português e que residem em uma cidade, na qual o alemão ${ }^{3}$ é muito pouco falado; como também, iii) elencar e refletir sobre os desafios de uma educação plurilinguística na família e na sociedade.

O artigo está organizado em cinco capítulos, que além desta parte introdutória, apresenta um apanhado teórico referente às características do bilíngue a partir de Mackey (1972), King e Mackey (2007) e Grosjean (2010) e nos tipos de bilinguismo infantil de Romaine (1995), além da nossa proposta de inclusão de mais um "tipo" de educação plurilinguística. A partir dessa discussão, no terceiro capítulo, descrevemos a experiência de uma educação plurilinguística vivida pelos autores com seus filhos em um país que se diz monolíngue. Além disso, elencamos elementos facilitadores e dificultadores de uma educação plurilinguística. No quarto capítulo, serão feitas reflexões sobre os desafios de uma educação plurilinguística, que garanta e viabilize a manutenção e promoção de línguas. Por fim, serão elencadas as considerações finais com a retomada dos nossos objetivos para este artigo.

\footnotetext{
${ }^{3}$ Tanto o alemão padrão, quanto as variedades regionais Deitsch/Deutsch.
} 


\section{Bilinguismo infantil: recorte teórico}

Sempre acreditamos que quanto antes aprendermos uma língua, melhor. Podemos dizer que muito disso tem a relação com a nossa própria trajetória de educação bilíngue na família. Para King e Mackey (2007), as vantagens de se aprender mais de uma língua na infância são ressaltadas por fatores como: internalização do sistema fonético da língua, aprendizagem mais lúdica, mente mais aberta e propensa ao aprendizado, ausência de vergonha para aprender. Os autores também ressaltam que as crianças normalmente estão desprovidas de preconceitos e assim vão evoluindo gradativamente, sem preocupação com um padrão a ser alcançado. Já os adultos, muitas vezes, veem-se obrigados a aprender, com tempo limite ou metas estipuladas e de terem várias atribuições além do aprendizado. Somase $a$ isso a vergonha perante a pronúncia na língua, pois acreditam que há uma forma única e ideal que deve ser preconizada e a dificuldade de emitir ou reconhecer sons diferentes daqueles da sua língua materna.

No nosso caso específico, planejamos que os estímulos em alemão já seriam iniciados com os filhos enquanto ainda estivessem no ventre da mãe. Foi necessário considerar muitas variáveis, pois a criança, que é um solo fértil para a aprendizagem, da mesma forma que aprenderia alemão, poderia, se existisse algum outro estímulo, através de filmes, leituras, músicas, jogos, mas também, em contato com uma colaboradora, vizinhos, parentes e amigos, aprender qualquer outra língua.

Romaine (1995), que busca analisar dados de pesquisa que considerem a aquisição bilíngue, conseguiu estabelecer seis tipos: "Tipo 1: Uma pessoa - uma língua" (p. 183); "Tipo 2: Língua doméstica não dominante, - uma língua - um ambiente" (p. 184); "Tipo 3: Língua doméstica não dominante sem apoio da comunidade" (p. 184); "Tipo 4: Duas línguas domésticas não dominantes sem apoio da comunidade" (p. 185); "Tipo 5: Pais não nativos" (p. 185) e "Tipo 6: Línguas mistas" (p. 185). ${ }^{4}$ Com os seis tipos, somos remetidos a realidades muito particulares que precisam ser consideradas para que possam ser compreendidas as diferentes possibilidades de se ter uma educação bilíngue.

Para fazermos uma reflexão sobre experiências vividas ou simplesmente para compreendermos como uma pessoa pode se tornar bilíngue, apresentaremos brevemente cada tipo proposto por Romaine (1995) para, ao final, podermos perceber com qual tipo a situação deste estudo de caso pode ser relacionada e por quê. Além disso, para podermos observar qual o método mais eficiente para educar uma criança bilíngue em diferentes circunstâncias.

Em se tratando do tipo 1, duas línguas nativas diferentes são faladas na família, ou seja, o pai fala uma língua e a mãe fala outra com o filho, no entanto, pai e mãe conversam entre si em ambas as línguas. Portanto, o exercício está nos pais, em se dirigirem ao filho sempre na

\footnotetext{
4 Type 1: One Person - on Language". (p. 183); "Type 2: Non-dominant Home Language, - On Language - on Environment." (p. 184); "Type 3: Non-dominant Home Language without Community Support." (p. 184); "Type 4: Double Non-dominant Home Language without Community Support." (p. 185); "Type 5: Non-native Parents." (p. 185) e "Type 6: mixed languages." (p. 185) (ROMAINE, 1995).
} 
mesma língua, na língua materna de cada um. Na comunidade, ou seja, fora da casa, é falada, no exemplo apresentado por Romaine (1995), a língua da mãe. Algumas conclusões de pesquisas sobre o tipo 1 apontam que bilíngues tornaram-se conscientes da arbitrariedade da natureza da relação entre palavra e sentido e que a noção de domínio de uma língua não é estática, ela varia conforme fatores de idade, gênero, classe, identidade, dentre outros. Hamers e Blanc (2000) também salientam que o bilinguismo não é estável e que muitos fatores contribuem para a sua manutenção ou substituição.

Para Romaine (1995), o tipo 2 também apresenta duas línguas nativas diferentes na família e ambas são línguas não dominantes. A estratégia, neste caso, está em os pais falarem a língua não dominante em casa e, na sociedade, a criança aprende a língua dominante que é, no exemplo apresentado pela autora, a língua que apenas um integrante da família também domina. Pesquisas desse tipo de Fantini (1985 apud Romaine 1995) apontam para uma consciência metalinguística da criança e o biculturalismo, pois cada língua (inclusive aquela que não é dominante) tem a sua cultura.

Se compararmos o tipo 3 com o tipo 2, só temos uma mudança a destacar, os pais falam uma mesma língua não dominante e, na sociedade, a criança entra em contato com a língua dominante, ou seja, os pais são os únicos responsáveis para ensinar a língua menos prestigiada, pois estão inseridos num ambiente com uma língua dominante que todos os integrantes da família não conhecem, mas possivelmente, aprenderão em virtude do seu contato social. Oksaar (1977 apud Romaine 1995) observou seu filho na aquisição do alemão, a sua terceira língua, aos 3 anos e 11 meses, quando passou a morar em Hamburgo, na Alemanha. A autora observou que seu filho, bilíngue em sueco e estoniano, ao aprender alemão, fazia transferências sintáticas e morfológicas de forma muito equilibrada, o que ofereceu evidências de que as crianças podem aprender mais de três línguas sem maiores problemas.

A única diferença do tipo 4, se comparado ao 3, é que são faladas duas línguas não dominantes na família sem suporte da comunidade. Poderíamos exemplificar esse tipo com a realidade dos haitianos que vivem no Oeste Catarinense, conforme observações e anotações feitas. Porém registramos que muitos imigrantes, pelo fato de sofrerem preconceito linguístico em escolas que não estão preparadas para receber alunos que não falam português, acabam deixando de falar suas variedades em casa, até por orientação de professores.

Horst e Bertiotti (2019) e Bernieri (2017 apresentam a realidade de escolas públicas, nas quais as crianças, sem muito esforço e de forma muito natural, vão aprendendo a se comunicar com os colegas de turma, primeiramente com gestos e, aos poucos, em português. A escola, através do seu corpo docente, pedagógico e administrativo, precisa, acima de tudo, empatia, boa vontade e conhecimentos básicos e assim, com esse incentivo, os imigrantes haitianos poderão continuar investindo no bilinguismo em suas famílias.

No tipo 5, os pais têm a mesma língua nativa, que é a língua da comunidade, e a estratégia assumida pela família é ensinar aos filhos uma língua que é estrangeira para um dos integrantes da família. Pesquisas de Döpke (1992 apud Romaine 1995), sobre esse tipo, 
indicam que, num primeiro estágio, a criança não percebe que a língua de casa e da comunidade são diferentes, mas num segundo momento, conforme a exposição que é feita com cada língua, começa a fazer uma distinção entre língua e contexto e, conforme a personalidade, postura dos pais e quantidade de exposição, a criança vai se tornando bilíngue, mesmo que a criança não tenha as mesmas experiências nas duas línguas.

Por fim, apresentamos o tipo 6, formado por pais bilíngues em comunidades bilíngues e, nesses casos, como mãe e pai dominam as duas línguas, estas acabam sendo misturadas e assim são passadas para os filhos conforme Tabouret-Keller (1962 apud Romaine 1995), possivelmente, dando origem a um crioulo. Em estudos realizados em comunidades bilíngues no RS, SC, PR e ES, onde os pais, também bilíngues, ensinam italiano-português, polonêsportuguês e alemão-português, por exemplo, nos remetem a línguas mistas, que têm função social entre os seus falantes. (ALTENHOFEN, 2003; CHRIST; PERES; ROCHA, 2019; DALLEASTE; BUSSE, 2016; HORST, 2014; HORST; KRUG; BERNIERI, 2019; KRUG; RUSCHEINSKY; HORST, 2019; KRUG; HORST; WEPIK, 2016; LARA, 2015).

Depois de apresentar os seis tipos de aquisição bilíngue, podemos destacar que não nos identificamos com nenhum tipo isolado, pois precisávamos considerar a nossa realidade no Oeste Catarinense: área de formação, interesse, identidade linguística, possibilidades futuras para manutenção da língua aprendida, acesso a meios diversos para uma máxima exposição à língua-alvo, dentre outras questões. Porém, mantivemos algo que consideramos adequado à nossa realidade e que tem relação com o tipo 1 de Romaine (1995): on person on language. Assim, propomos um tipo 7: pais e filhos residem no país de origem e falam uma Língua Estrangeira, doravante, LE, em casa, ou seja, na sociedade é falada a língua oficial do país e em casa é falada a LE. Entendemos que a experiência que vivemos e que apresentamos e descrevemos neste artigo tem relação com a proposição feita, uma vez que não nos identificamos com nenhum tipo apresentado por Romaine (1995).

Optamos por ensinar aos nossos filhos o alemão, pois, por ser a língua que dominamos, não seria difícil propiciar a eles um ambiente familiar, quase que exclusivamente, nessa língua. Vale destacar que a primeira língua falada pelos pais foram as variedades de imigração Deitsch/Deutsch ${ }^{5}$, enquanto alemão foi aprendido por ambos fora do ambiente familiar, a partir dos 11 anos, na escola, no caso da mãe, e com mais de 20 anos de idade, em escola de idiomas, no caso do pai. Essa decisão foi uma grande oportunidade para nos mantermos fluentes na língua, mas também para comprovarmos que aprender línguas precocemente faz diferença positiva na vida do aprendiz. É de suma importância destacar que nossos familiares mais próximos, teuto-brasileiros, são falantes de variedades distintas do alemão: Deitsch/Deutsch e nossos filhos têm contato com essas línguas através dos familiares, como descreveremos mais detalhadamente no próximo subtítulo.

\footnotetext{
${ }^{5}$ Consideramos, com base em Altenhofen (2016), o Hunsrückisch do tipo Deutsch como referindo-se à variedade próxima ao standard, enquanto o Hunsrückisch do tipo Deitsch refere-se à variedade [+dialetal], no nosso caso, mais Hunsrückisch.
} 


\section{Experiências de uma educação plurilinguística em um país que se diz monolíngue: facilitadores e dificultadores}

Educar filhos bilíngues de forma consciente e planejada, é algo pouco comum no Brasil, pois, segundo Bagno (1999) e King e Mackey (2007), há mitos presentes na sociedade, como por exemplo, saber duas línguas só será relevante, quando se opta por línguas prestigiadas, ou ainda, somente pessoas com um grau de proficiência elevado na língua-alvo terão sucesso na tomada de decisão. Muitos dialetólogos/sociolinguistas conseguem criar oportunidades para pesquisas linguísticas a partir de situações vividas com os filhos e nós, também, estamos vivenciando tal experiência. Nesse sentido, os dados aqui apresentados são oriundos das observações, fotos, portfólio (instrumento avaliativo usado na escola) e anotações em cadernos de campo, que fazemos do desenvolvimento linguístico dos nossos dois filhos que hoje têm nove e seis anos, doravante (F1) e (F2), respectivamente. Também vale ressaltar que não vamos nos ater no artigo a discutir sobre quantas línguas são conhecidas pelos informantes, mas sim, ao fato da família criar a oportunidade consciente para os filhos aprenderem, em casa, uma língua (ou até mais línguas), diferentes da língua oficial do país em que residem.

Atualmente, vivemos em uma cidade com mais de 200 mil habitantes, no oeste de Santa Catarina, que não tem uma escola bilíngue português-alemão e tampouco uma escola que ofereça alemão em seu currículo. Também temos pouco ou quase nenhum contato com outros falantes desta língua, pelo fato de a cidade ser originalmente e majoritariamente colonizada por descendentes de italianos e, em número bem inferior, de descendentes de alemães.

Nossos dois informantes falam fluentemente alemão e português com os pais e interagem com as avós e demais familiares em Deitsch/Deutsch, variedades alemãs. Tanto com F1 quanto com F2, percebemos muito entusiasmo, interesse e facilidade no aprendizado das línguas estrangeiras na escola, pois fazem comparações entre o português, alemão e as línguas ensinadas.

F1, com apenas uma aula de inglês e uma de espanhol por semana, já consegue formular frases e conduzir uma comunicação básica nessas línguas. Em alguns casos, na falta de vocabulário, F1 faz uso tanto de português quanto de alemão, para completar a frase. Essa característica é típica de bilíngues, conhecida como code-mixing, quando o indivíduo inicia a frase em uma variedade e continua em outra, alternando as línguas, conforme necessidade, sem que haja perdas na comunicação (APPEL; MUYSKEN, 1996).

Segundo Muysken (2007), os campos de troca de código e interferência morfossintática são organizados como domínios de investigação separados. O autor destaca que é indiferente se considerarmos gramática, fonologia ou léxico, são sistemas linguísticos distintos em contato, situação vivenciada por F1, no relato apresentado acima.

Considerando o contato de F1 e F2 com quatro diferentes variedades linguísticas no círculo familiar, destacamos algumas curiosidades levantadas por eles: F1, por volta dos 2,5 anos de idade, sem juízo de valor, observou que a língua que falávamos em casa era diferente 
daquela falada pela avó paterna, assim como, por volta dos 5 anos, passou a destacar que as avós tinham algumas marcas fonéticas que ele desconhecia na sua, como, por exemplo, a troca do uso das plosivas bilabiais sonoras por surdas /b/ e /p/, /b/ala por /p/ala e as labiodentais /d/ e /t/, /d/inheiro por/t/inheiro e do /r/ tepe e da vibrante. Este fato confirma o exposto por Döpke (1992 apud Romaine 1995), no tipo 5 de Romaine, ou seja, a criança começa a observar as diferenças linguísticas a partir da sua bagagem linguística.

Esse reconhecimento dos sons distintos dos fonemas por crianças bilíngues que ainda não estão alfabetizadas permite inferir que o contato com duas línguas ou mais, de forma precoce, propicia ao indivíduo criar uma sensibilidade auditiva e consequente facilidade em perceber as diferenças, neste caso, das variantes fonéticas de uma língua. Vale destacar que o contato com as avós não é diário, mas suficiente para que haja uma identificação com as línguas faladas por elas, pois a língua tem relação direta com uma pessoa e a identifica. A partir da nossa percepção, podemos destacar que os comentários feitos por F1 e F2 não carregam nenhum sentimento de superioridade ou inferioridade, possivelmente por ocorrerem no ambiente familiar, e ajudam a fomentar o sentimento de respeito perante à diversidade que, facilmente, depois de ter sido um conhecimento do qual a criança tenha se apropriado no lar, possa ser replicado em outros espaços. Compreendemos que estamos investindo numa educação plurilinguística (ALTENHOFEN; BROCH, 2011; BROCH, 2014) na família, pautada na sensibilização perante as suas línguas e as do outro, mas sem deixar de investir nas diferentes habilidades que podem ser desenvolvidas a partir de uma língua.

F2, aos três anos, teve a oportunidade de conviver, por um período de três semanas, com famílias alemãs, incluindo crianças. Na ocasião, foi possível observar a sua tranquilidade para se comunicar. Também vale comentar uma situação vivida por F1 e F2, com sete e quatro anos, respectivamente, quando ouviram uma história lida por uma alemã, ambos não apresentaram dificuldade na compreensão do que estava sendo lido em voz alta. Quando não entendiam algum trecho do livro em alemão, imediatamente solicitavam esclarecimento também em alemão. Chama a atenção o fato de não estranharem a fala de uma alemã, mas estranharem a fala das avós. Isso permite supor que o contato com alemão por meio de filmes, músicas, falando com os pais e até pelo contato pessoal com amigos alemães, fez com que eles se familiarizassem mais com a variedade padrão do que com as variedades das avós, até pelo contato com menor intensidade e frequência com as últimas.

A capacidade da compreensão oral do bilíngue precoce também chama a atenção, pois é uma habilidade que normalmente, na aprendizagem de uma LE na escola, requer mais tempo para que ocorra, possivelmente pelo contato com a língua-alvo ser, normalmente, uma a duas vezes por semana e ficar restrito à educação formal.

Considerando as diferentes habilidades, vale ressaltar que F1 fala fluentemente tanto alemão quanto português e, além disso, domina as habilidades de leitura e escrita de alemão, sem ter frequentado, até o presente momento, nenhuma aula nessa língua. Em português, F1 desenvolveu as habilidades de leitura e escrita na escola a partir dos três anos de idade. Já o informante $\mathrm{F} 2$ encontra-se na fase de aquisição da leitura e escrita em português e, também, já consegue ler e escrever palavras e pequenas frases em alemão. 
Propiciamos aos nossos filhos ambientes em alemão, nos quais fosse lido, falado, cantado e até mesmo, quando partisse do interesse das crianças, escrito na língua da família. Tais ambientes em alemão foram criados a partir da contratação de uma colaboradora fluente na variedade alemã regional Hunsrückisch, como também com a seleção de filmes, ao lado de conversas online com filhos de alemães da mesma idade, conversas com as avós, tios e tias, incentivo ao canto de músicas infantis e clássicas, contação de histórias, leituras, brincadeiras, conversa em alemão no ambiente familiar e muita dedicação e persistência com o estabelecimento de metas e adequações por parte dos pais quando necessário. A criação desses ambientes corrobora o que Moroni e Gomes (2015) trazem a respeito da percepção da realidade linguística familiar e da cultura dominante.

Tão relevante como a transmissão de uma língua de herança são as tensões e as relações que emergem destes indivíduos, isto é, sua percepção da realidade, o contato e a interação com a cultura dominante e a cultura da família, e como este sujeito percebe a língua do entorno e a língua de herança (MORONI; GOMES, 2015, p. 24)

Para Mackey (1972) e Grosjean (2010), o bilíngue utiliza as suas línguas com diferentes pessoas, em diferentes domínios da vida e para diferentes propósitos. Assim, considerando que os usos linguísticos são diferentes, é compreensível que o domínio e a fluência do indivíduo não sejam iguais nas diferentes línguas.

Ainda, com o interesse de que esse rol de estímulos em alemão fosse, de fato, o que de melhor poderíamos oferecer aos nossos filhos, a contratação de uma colaboradora que falasse a variedade alemã regional foi estratégica, pois como ela iria passar muitas horas do dia com F1, essa escolha foi fundamental para o aprendizado de alemão. A experiência foi positiva, pois quando F1 completou 3 meses de vida, a colaboradora já passou a se inteirar daquilo que seria a sua atividade, a contar do término da licença maternidade da mãe, convivendo assim, com nossa família, desde muito cedo.

O motivo pelo qual os jovens deixam de falar Deitsch/Deutsch e se tornam monolíngues em português sempre nos chamou a atenção. A partir de anotações nos cadernos de campo, referentes às pesquisas que realizamos para os projetos Atlas Linguísticocontatual das Minorias Alemãs na Bacia do Prata - Hunsrückisch (ALMA-H), (ALTENHOFEN, 2016) e Atlas das Línguas em Contato na Fronteira (ALCF), (KRUG; HORST, no prelo), encontramos alguns indícios dessa ruptura. Um dos motivos relatados, e que para nós está bem claro, é a falta de incentivo por parte dos pais, que, por sua vez, seguiam o mito de que seus filhos teriam problemas com o aprendizado de português nas escolas por falarem a variedade alemã. Outro motivo é de os pais não repassarem a sua língua de contato aos filhos por medo de que estes iriam sofrer preconceito e maus tratos, como os próprios pais ou avós sofreram em épocas de ditadura militar. Um terceiro motivo era a falta de contato com materiais como livros, filmes, revistas, jogos etc. editados na língua do imigrante, o que hoje, com a evolução da tecnologia e dos meios de comunicação, pode ser minimizado para o aprendizado da variedade. O último motivo, que envolve todos os anteriores, é o desinteresse por parte dos jovens por uma variedade linguística sem prestígio, no caso específico dos dados 
do ALMA-H, vista também como a variedade do agricultor/colono, dos avós, uma língua dos velhos e nada habitual entre os jovens.

Krug $(2004$, p. 90) comenta que os jovens não falam mais a variedade entre si, pois não a aprenderam ou por sentirem vergonha. Geralmente culpam os mais velhos de não terem repassado a variedade, enquanto os mais velhos culpam os jovens de desinteressados pelo aprendizado da variedade e até se sentem envergonhados em falar.

(...) a falta de uso social e escolarização nessa língua podem provocar a perda de seu domínio e, por consequência, fazer com que deixe de ser uma prioridade na vida do falante. Diante deste cenário, o papel da família é decisivo no processo, já que é a partir dela que a criança pode ter acesso e construir um vínculo com esta língua e esta cultura e, para isso, é necessário que a família decida transmitir a língua aos filhos, o que nem sempre acontece, pois os pais podem optar por adotar a língua do entorno e abandonar seu idioma materno. (MORONI; GOMES, 2015, p. 24)

O português nunca foi a nossa preocupação em casa, pois fora do ambiente familiar todo o contexto é nessa língua e o convívio com outras crianças e outros ambientes, que não seja o de casa, propicia a eles todo o respaldo de que necessitam. Em outras palavras, foi criado um ambiente familiar em alemão, onde o português é utilizado somente em última necessidade. E chegou o dia em que tivemos que contratar uma colaboradora que não falava nenhuma variedade de alemão, mas era graduada em inglês, o que, até certo ponto, foi inspirador, especialmente para F1, que tinha cinco anos. F2 tinha dois anos de idade, quando ocorreu a troca de colaboradora, com isso, o estímulo em alemão ficou a cargo dos pais e do irmão mais velho, além dos filmes, canções, leituras e jogos à disposição diariamente. Com esse fato, F2 entrou em contato com o português muito mais cedo em comparação com F1.

Tanto F1 quanto F2 tiveram alemão como primeira língua e somente depois dos três anos de idade, no caso de $\mathrm{F} 1 \mathrm{e}$, dois anos e seis meses de idade, no caso de $\mathrm{F} 2$, ao ingressarem na escola, começaram a ter um maior contato ativo com o português. Em se tratando do ingresso no ambiente escolar, vivemos experiências desconfortáveis em entrevistas quando fomos conhecer escolas na cidade para matricular F1, tanto por parte da direção, quanto por parte da coordenação pedagógica de algumas instituições de ensino visitadas. O fato de F1 ter alemão como primeira língua causou, primeiramente, um sentimento de dó e lamento pela condição da criança, mas também, de impotência e desconhecimento por parte da escola de como lidar com um caso assim, nunca antes vivido ou não considerado pela escola, pois a escola está ocupada em ensinar em português. Uma professora, inclusive, sugeriu que começássemos a falar em português com nossos filhos, para que eles sofressem menos na escola, e destacamos que este comentário foi feito por uma professora de língua estrangeira, descendente de imigrantes alemães.

Com as reações descritas, é possível sentir o preconceito linguístico, mas também, nas reações dos professores em função de direção e coordenação pedagógica, é possível inferir o quão desconhecida é a realidade de crianças bilíngues na escola básica no Brasil. Altenhofen (2004), assim como King e Mackey (2007), discorrem sobre esse mito que desencoraja muitos pais e professores a estimularem e experimentarem uma educação plurilinguística. 
Diferentemente, Bernieri (2017), em um estudo preliminar, de maneira geral, registra que professores da educação básica do Oeste Catarinense, mesmo não tendo uma formação específica sobre o assunto, se sentem motivados e sensibilizados para lidar com crianças bilíngues, sejam estas de variedades italianas, alemãs ou de imigração recente, haitianos e venezuelanos. Uma informante, inclusive, destaca a importância de ser bilíngue:

Penso que é fundamental, é muito, muito, muito importante que a criança aprenda uma segunda língua sim, principalmente desde pequenininha porque a gente sabe que de acordo com estudos, é nos primeiros anos que se formam mais conexões, mais sinapses alí que permitem com que a criança aprenda mesmo, por isso eu penso que quanto antes aconteça o contato com uma segunda língua, melhor, né porque vai ser mais fácil, é uma terra mais fértil ainda... o cérebro da criança, quanto menor, melhor. Por isso penso que além do português é muito importante que as crianças aprendam uma outra língua, que daí a escolha dos pais, seja qual ela for, mas é uma oportunidade que não pode deixar passar. - Professora A (BERNIERI, 2017, p. 141)

Como já destacado anteriormente, não encontramos escola bilíngue, tampouco uma escola que tivesse a língua alemã como disciplina em seu currículo, mas encontramos uma escola aberta à diferença. F1 teve uma valiosa experiência ao ingressar no infantil 3 de uma escola particular, pois nessa turma havia uma auxiliar docente, que entendia Deitsch e abraçou a causa, juntamente com a professora regente, esta última, também descendente de imigrantes alemães, mas não falante. As professoras pediram o auxílio de seus familiares para poder lidar com o novo aluno e anotaram algumas frases, como por exemplo; "Quer tomar água?", "Precisa ir ao banheiro?", "Está na hora do lanche.", "Você está bem?" Partindo dessa experiência, podemos argumentar que, além da professora auxiliar ter retornado às origens e ter se interessado pela variedade que abandonou na juventude, esta profissional ganhou o carinho, a confiança e a atenção de F1. Essa atitude foi positiva para todos e comprovou que sem preconceito e sem estigmatizar a/s variedade/s trazida/s por F1, o aprendizado do português pôde ser muito produtivo e sem prejuízos e traumas, especialmente, para a criança. Percebemos que este pode ser o caminho para as diferentes variedades linguísticas caminharem juntas, dividindo o mesmo espaço, sem que uma seja estigmatizada perante a outra como afirma uma das professoras de F1:

Com a chegada do F1 na turma, aprendi muito, além de um pouco da língua, aprendi e observei o quanto era importante ter uma educação bilíngue, afinal até então, o F1 só tinha contato com a língua alemã, mas a partir da escola, a língua portuguesa passou a fazer parte da sua rotina. Rapidamente, ele começou a expressar-se em português, de modo que algumas vezes, trocava algumas palavras ou na dúvida perguntava para nós: "Profe, como é no português?" Então a professora colaborava ainda mais, porém, muitas vezes escrevíamos na agenda, relatando o contexto para família colaborar nos ensinando o significado do que o F1 quis manifestar na tarde. Como é bom aprender uns com os outros! (Registro no portfólio de F1 - 2014. O uso para fins de pesquisa foi autorizado pela autora, conforme declaração enviada à revista)

Como é possível perceber no relato acima, sempre que F1 respondia em alemão em sala de aula, as professoras não o corrigiam, não ironizavam, mas sim respeitavam e tentavam 
auxiliar na compreensão, o que se tornou um hábito entre os coleguinhas. Diferentemente, Guy e Zilles (2006) descrevem o que ocorre em relação ao ensino da variedade padrão do português, considerando a variedade falada pelos alunos em casa e nas suas comunidades de origem:

O ensino da variedade padrão, no entanto, é feito com uma metodologia e uma ideologia muito estranhas. A professora costuma fingir que isso que ela quer promover é a única forma certa da língua, e qualquer palavra, pronúncia ou estrutura que esta variedade não admita é tratada como um desvio, um erro, uma falha, burrice, preguiça ou até má vontade ou rebeldia da criança. (GUY; ZILLES, 2006, p. 41)

F1 também sempre foi incentivado pelas professoras a levar questões da sua língua de casa a título de curiosidade, para compartilhar com seus colegas e professores, como por exemplo, os números, cantos, rimas, estruturas frasais e, inclusive, livros em alemão. Essa é mais uma forma respeitosa de se lidar com a língua do outro, seja ela materna, oficial do país ou estrangeira, em um país que luta contra o preconceito linguístico. Destacamos uma atividade registrada no portfólio de F1 intitulada "O que os meus amigos podem aprender comigo?" que consistia em dar a liberdade para cada criança, com a ajuda da sua família, a escolher algo que gostaria de ensinar. F1 ensinou um versinho matemático em alemão para os colegas com apresentação de cartaz, que ficou exposto na escola, assim como todos os trabalhos apresentados, para compartilhar com a comunidade escolar.

Ainda, destacamos a fala de uma das professoras de F1:

Hoje, observo o quanto a educação bilíngue oportuniza a criança a viver oportunidades que só serão vividas, devido ao esforço da família em manter-se firme nesse pensamento de ensinar a língua alemã, como primeira língua, afinal, a língua portuguesa foi aprendida pelo F1 de maneira tranquila e feliz. Sabemos que a mente da criança é um campo fértil para aprender e se desenvolver então, que bom aproveitar a primeira infância para construir conhecimento, conhecimento esse que certamente abrirá muitas oportunidades na vida. (Registro no portfólio de F1 - 2014)

Quanto à aprendizagem da português por F1, foi algo natural, pois depois de três semanas, F1 já estava fluente na português, ou seja, ele falava suas línguas com alguns casos de code-mixing, que segundo King e Mackey (2007), é um processo pelo qual crianças bilíngues podem passar e que não é um sinal de confusão das línguas. Vale ressaltar que F1, como já dito anteriormente, desde cedo, foi posto em contato com a fonética tanto de alemão, quanto do português, o que permitiu que ele adquirisse muito cedo a consciência fonológica dos vocábulos (ILHA; LARA; CÓRDOBA, 2017).

Como podemos ver na figura 1, um dicionário bilíngue escrito por $\mathrm{F} 1$ aos cinco anos de idade para uma colaboradora que não sabia alemão. 
Figura 1 - Dicionário bilíngue alemão-português de F1

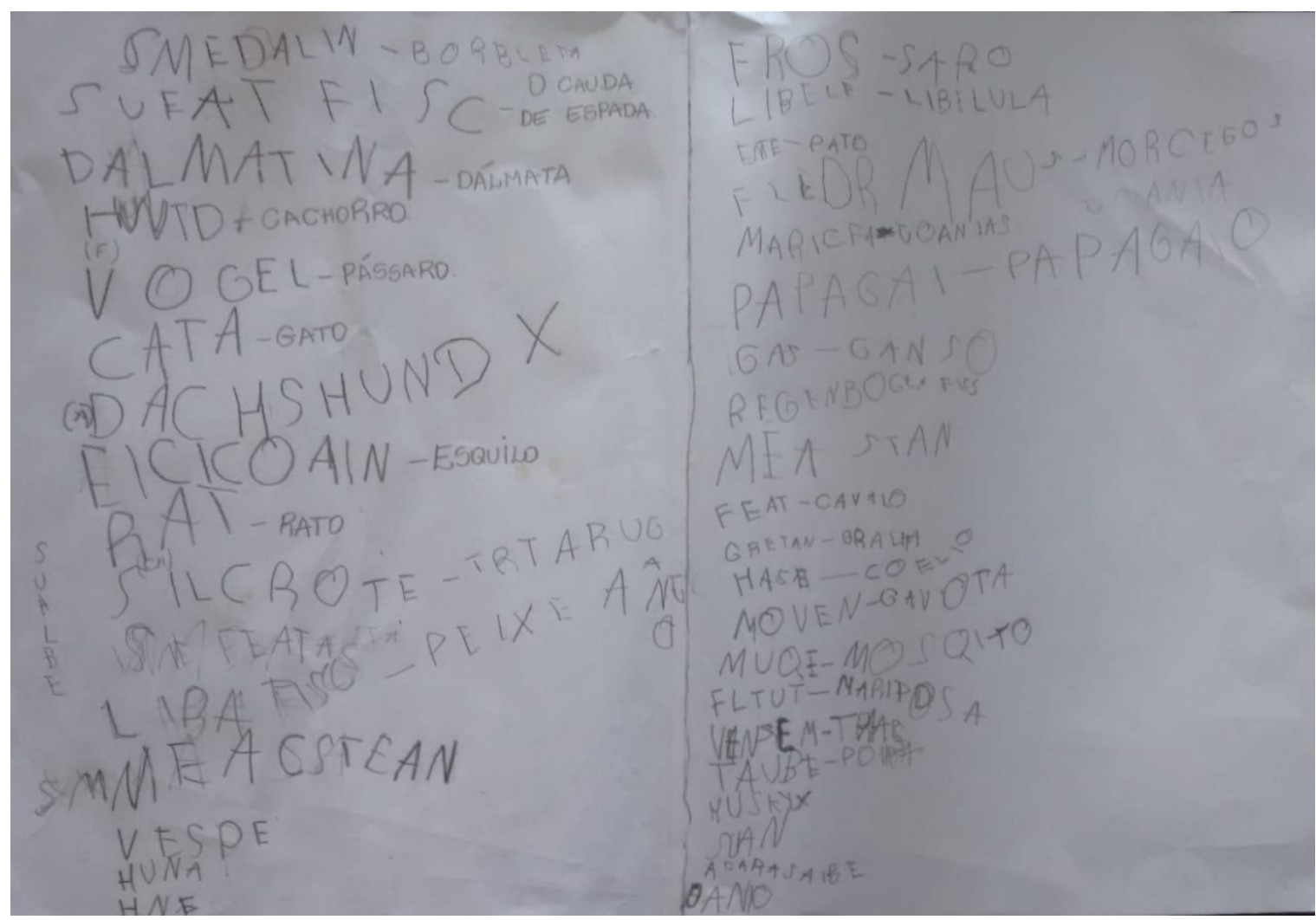

Fonte: Arquivo pessoal.

Percebe-se a preocupação por parte de F1 de que a colaboradora não entendesse a fala do irmão, enquanto os pais e ele estivessem fora. Quanto à escrita, nota-se que principalmente os sons palatais em alemão ainda não estavam internalizados na escrita de F1, mas bastante avançados para a sua idade.

F1 teve professores com uma maturidade para trabalhar com ele essa desenvoltura em dominar e falar línguas. Em alguns momentos, F1, inclusive, foi chamado para intermediar a conversa entre visitantes alemães e docentes do colégio ou também colaborando no entendimento entre as professoras e o irmão (F2). Porém, em um ano específico, tivemos a impressão de que F1 não se sentiu mais tão confortável em relação ao uso de alemão na escola como anteriormente. Quando questionado sobre o motivo, interpretamos que ele possa ter sofrido preconceito linguístico e, com muita discrição, procuramos dialogar sobre o seu sentimento, sobre a vida em sociedade e outros pontos relacionados à heterogeneidade linguística e foi possível amenizar a situação.

Desconfiamos que F2 também sofreu algum tipo de preconceito linguístico que o intimidou a falar alemão, pois certo dia, reproduziu o seguinte comentário: "moramos no Brasil e devemos falar português", quando reforçamos que ele devesse se dirigir aos pais em alemão. A partir do sentimento de $\mathrm{F} 2$, também procuramos refletir conjuntamente acerca das diferenças de cor, de grupo étnico, de classe sociocultural, mas também de língua, tentando deixá-lo à vontade e seguro para continuar a falar a língua que aprendeu em casa em todos os espaços e com quem se sentisse à vontade de fazê-lo. 
A partir da formação plurilíngue dos pais e, por trabalharem questões de preconceito linguístico e heterogeneidade linguística na sala de aula a nível universitário, também foi possível estabelecer um diálogo com a escola a partir do que nossos filhos manifestaram, também no sentido de colaborar com a formação docente, trazendo informações sobre os benefícios do bilinguismo e da importância do respeito à diversidade linguística, especialmente, no espaço escolar. Mais uma vez, foi possível notar que a insistência e o esforço dos pais em manter uma educação plurilinguística dos filhos e uma escola sensível à diversidade faz com que seja rompido o estigma de que falar mais de uma língua na infância atrapalha no aprendizado da língua da escola.

Ainda vale ressaltar que registramos, a partir de experiências vividas como professores formadores, que quando um professor se depara com um aluno bilíngue e, pela dificuldade de sair da zona de conforto ou, até por desconhecimento, prefere manter um discurso de monolinguismo. Esse professor possivelmente não sabe o quanto a língua materna da criança representa para ela. Assim, muitas vezes, em consonância com os professores, os pais desistem de manter o uso das suas línguas maternas/minoritárias no seio familiar, o que é uma grande perda para o indivíduo. A solicitação ou comentário de um professor deixa a maioria dos pais sem argumentos para seguirem falando a variedade não oficial do país com seus filhos.

Como já mencionado anteriormente, F2 ingressou na escola aos dois anos e seis meses de idade e ele também só falava alemão, mas já tinha uma bagagem cultural no português bem mais avantajada em comparação com o ingresso de $F 1$, mas se comunicava unicamente em alemão. As professoras de F2 eram de descendência italiana e o estimulavam a falar tanto alemão quanto português. Em um relato extraído do portfólio de F2, a professora escreveu o seguinte:

Quando começou na escola, o F2 falava no idioma alemão. No início tivemos
dificuldade em nos comunicar com ele. Durante a tarde não desenvolvia nenhuma
fala ou diálogo com os colegas e professoras, mesmo quando era questionado sobre
a família ou algo sobre ele mesmo. (...) Registramos o dia 4/10, quando estávamos
indo ao parque e era uma tarde linda, ensolarada e o F2 manifestou: "Profe, não 'tá"
chovendo!" (...) inicialmente o F2 apresentou dificuldades de relacionamento. (...) o
fato de conseguir comunicar-se durante as brincadeiras colaborou para a formação
de vínculos afetivos e para o cultivo das amizades. (Registro no portfólio de F2 - 2016)

F2 diferencia as suas línguas pelos ambientes, pelas situações, leituras e pessoas. 0 contato com o português, no caso de F2, ficou mais intenso a partir dos dois anos de idade. Os motivos para tal foram; além do ingresso de $\mathrm{F} 2$ na escola, das atividades a serem feitas em casa, da visita de coleguinhas, e o contato com outras crianças em atividades extraclasse, também houve a troca da colaboradora falante de alemão, por uma não falante. Todos esses fatores corroboraram com que o contato com o português se intensificasse no ambiente mais familiar.

Em se tratando da escrita, F2 também está aprendendo a escrever a partir da fonética e consciência fonológica e não pela silabação, e isso, nas duas línguas concomitantemente. Como podemos ver nas imagens abaixo (figura 2), registros espontâneos de escrita, F2 ainda 
não consegue realizar graficamente os sons palatais, nasais e os sibilantes e ainda escreve assim como ouve a pronúncia dos vocábulos, como por exemplo, nas palavra "lieber Papa" (querido papai) escreve "libapapa" ou ainda em português, "bolhia Dsabãu" (bolha de sabão), "bricei couno" (brinquei com o UNO). Nestes dois últimos exemplos, é notório que F2 ainda não internalizou e nem associou alguns sons à grafia ou vice-versa. Observamos a inclusão de um /i/ em "bolhia" e a elipse da vogal em "dsabãu", o que condiz com o falar rápido da sentença. Da mesma forma em "brincei", F2 registrou o /k/ no lugar de "qu" e, na sequência "couno", transcreveu literalmente os sons da fala.

Figura 2 - Registros espontâneos de escrita de F2

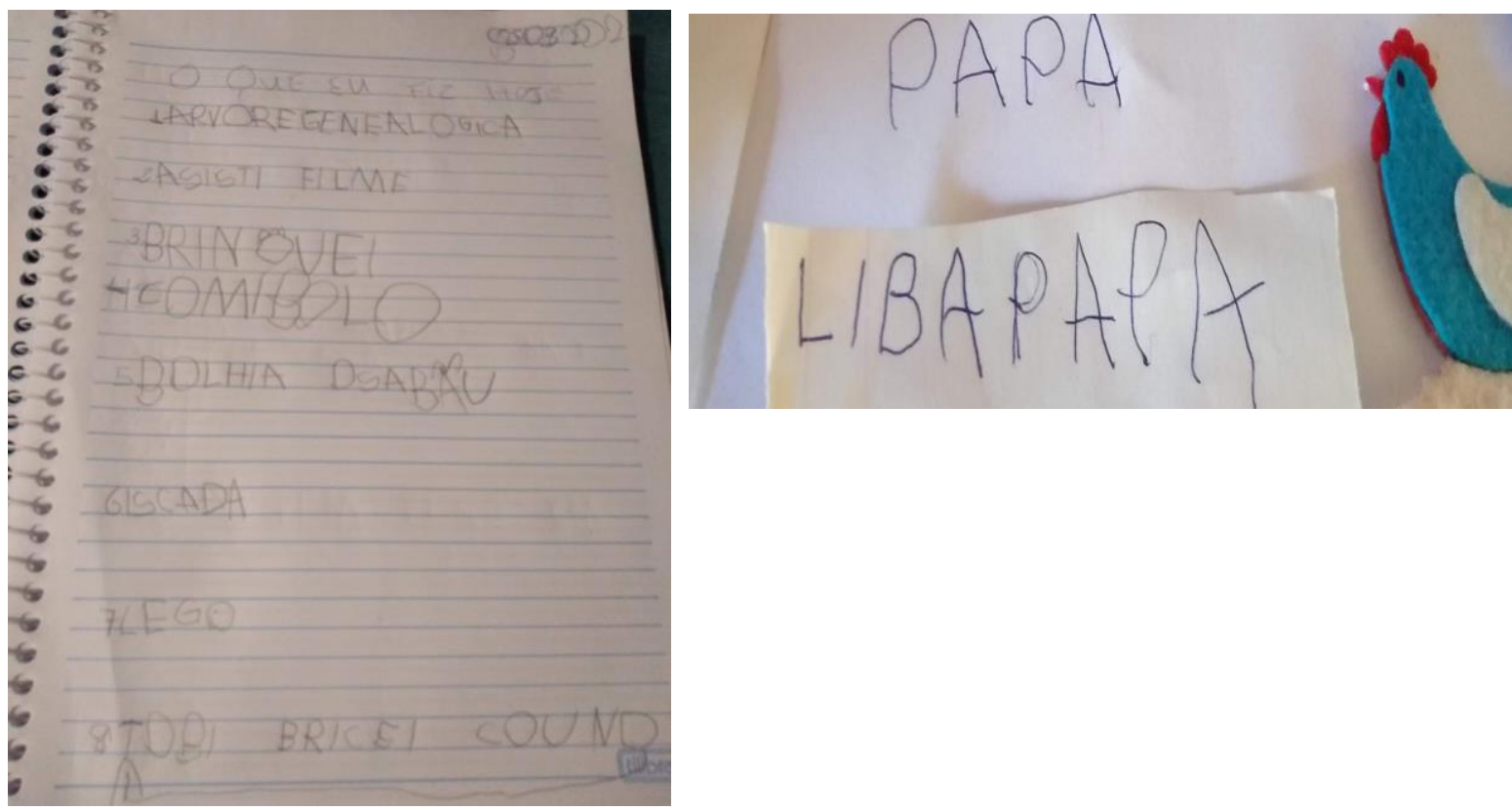

Fonte: Arquivo pessoal

Ao analisarmos a escrita de F1 e de F2, podemos dizer que o fato de serem bilíngues/ plurilíngues em nada influenciou ou está influenciando em F2, que ainda está em processo de alfabetização, na troca das plosivas surdas por sonoras ou vice-versa, o que pode servir para refutar a ideia de que essa seja uma característica de bilíngues alemão-português.

Sem dúvida, encontramos um campo fértil para, cada vez mais, incentivar o aprendizado de outras línguas, as línguas estrangeiras ensinadas na escola, por exemplo, e a facilidade que ambos têm em relacionar uma com a outra língua sem prejuízo.

A partir da experiência que vivemos em nossa casa, com filhos bilíngues/plurilíngues, podemos afirmar que é possível ser bilíngue desde a mais tenra idade, mas que para isso é preciso conhecimento, planejamento e atitude. Comprovadamente, pela experiência vivida com o ingresso dos filhos na escola, com três anos e três meses e, dois anos e seis meses, respectivamente, F1 e F2, é possível aprender português. Para Grosjean (2010), o bilíngue faz usos distintos das suas línguas, considerando os diferentes domains (domínios), ou seja, o indivíduo seleciona suas línguas conforme as situações, locais de uso e pessoas envolvidas, 
por exemplo, no caso de Pomerode, uma cidade em Santa Catarina, quando o português é usado somente para escrever, com autoridades, no clube; o alemão na igreja, e as duas línguas são usadas no trabalho, na família e com amigos.

Ainda, conforme o relato de uma professora de F1, quando estava no Infantil 3A:

A adaptação do (...) na escola foi tranquila, de maneira que muitas vezes observamos ele em sala, já nos primeiros dias de aula e ficávamos surpresas como a turma e ele estavam se socializando bem, afinal, apenas uma língua diferente existia entre eles e isso para crianças, não é nenhuma dificuldade, pois conversavam e se entendiam, através de gestos, movimentos, olhares, sorrisos de crianças. (Registro no portfólio de F1 - 2014)

Também a professora de F2, especificou no parecer descritivo do seu portfólio no Infantil 2B:

Na realização das atividades nos comunicávamos através de gestos, mostrando a ele o que deveria fazer. Passando alguns meses, (...) já estava se relacionando verbalmente com os colegas e professoras. Chegando ao final deste ano letivo, dia após dia, descobre e utiliza-se de palavras novas, o que é surpreendente de observar e ouvir. (Registro no portfólio de F2 - 2016)

O trabalho conjunto da escola, através das professoras das turmas e a família, foi fundamental. Pensando na especificidade de cada situação, que King e Mackey (2007) apresentam, quando destacam que o fato de os pais agirem de formas semelhantes com seus filhos em relação ao ensino bilíngue, inevitavelmente, não trará resultados iguais e sim, aqueles condizentes com a realidade de cada criança. Como exemplo, podemos citar, aptidão, interesse, idade, personalidade, estilo de aprendizagem e precisa haver empenho por parte da família junto com o apoio da escola, no sentido de não estigmatizar o falante bilíngue, mas sim, incentivar.

A realidade bilíngue é mais presente nas escolas públicas, que estão recebendo a maioria das crianças oriundas das imigrações recentes, no caso dos haitianos e venezuelanos, por exemplo, o que exige dos profissionais da educação um esforço dobrado. Já nas escolas particulares, como no caso de F1 e F2, que estudam em uma escola particular, a realidade bilíngue é mais uma exceção do que uma regra. Mesmo as escolas públicas não podendo oferecer as mesmas condições de espaço e ambiente de estudo, normalmente propiciadas pelas particulares, a tarefa de acompanhar de forma mais individualizada cada aluno advindo de imigração recente, deveria ser mais intensa, não só no sentido de introduzi-los na língua e cultura do Brasil, mas principalmente, de conscientização e valorização da própria cultura e língua dos imigrantes. Manter uma língua de imigração num ambiente em que ainda existem mais falantes daquela variedade é mais fácil do que no ambiente de F1 e F2, porém, a falta de conhecimento de como lidar com tal situação e a falta de recursos no ambiente escolar fazem com que a maioria dos profissionais da educação opte pelo caminho mais fácil, ou seja, o de não sair da zona de conforto e simplesmente não saber como lidar com o novo aluno e as novas oportunidades que dali poderiam ser alavancadas. 
A partir da descrição da experiência de uma educação plurilinguística vivida na família, elencados elementos facilitadores, dentre os quais destacamos: i) conhecimento sobre bilinguismo/plurilinguismo, ii) a possibilidade de criação de um ambiente em que a língua-alvo esteja em uso e iii) a motivação, o planejamento e a adaptação constante dos envolvidos para não perder de vista a meta a ser alcançada; mas também, os dificultadores de uma educação plurilinguística, tais como i) o mito existente na sociedade de que crianças que aprendem mais de uma língua precocemente terão muitas dificuldades na escola, ii) o preconceito linguístico, que é fruto de uma educação centrada na crença da necessidade de uma homogeneidade linguística e iii) a falta de uma política linguística sensível ao plurilinguismo, tanto de línguas minoritárias, quanto de línguas chamadas "modernas" na sociedade de maneira geral.

\section{Reflexões sobre os desafios de uma educação plurilinguística}

Pela experiência na educação superior desde 2010, mas também pela nossa experiência como professores de português e alemão como língua estrangeira na escola básica, podemos afirmar que há poucos espaços de formação, que capacitam professores para atuar no ensino de português ou língua estrangeira na educação infantil, considerando contextos de multilinguismo. Normalmente é o professor regente, formado em pedagogia que, com muito esforço, pela sua prática, vai se capacitando para trabalhar questões de aquisição de linguagem e alfabetização com suas crianças, que podem ter português como língua materna ou não. Já quando se trata da $L E$, normalmente é um professor graduado naquela língua, mas que foi preparado somente para trabalhar com crianças a partir do 60 ano, ou seja, ele precisa saber se adequar e adquirir alguns conhecimentos de como ensinar uma LE para crianças que ainda não foram alfabetizadas ou estão em fase de alfabetização, de repente, falantes de mais de uma língua.

Na escola básica, não somente pela experiência descrita no presente artigo, mas também com base em estudos anteriores de Bernieri (2017) e Horst e Bertiotti (2019), é possível observar os grandes desafios experienciados pelos professores, pois as turmas, cada vez mais, estão se tornando linguisticamente heterogêneas. Essa realidade, de grupos linguisticamente distintos na mesma sala de aula, já é vivenciada por muitos países pelo mundo afora, com destaque para a Alemanha e Itália e, se pensarmos na realidade linguística do Brasil, com as línguas indígenas, africanas e línguas de imigrantes europeus e asiáticos (portugueses, alemães, italianos, poloneses, japoneses, libaneses, entre outros) já vivemos uma situação linguística de contato de línguas há séculos em sala de aula, mas que, por questões políticas ou de política linguística, foram estigmatizadas e até, proibidas (ALTENHOFEN, 2004).

Com a abertura das fronteiras à imigração recente, primeiramente de imigrantes haitianos, depois de senegaleses, seguidos de sírio-libaneses e atualmente de venezuelanos, aumentou consideravelmente o número de alunos nas escolas que não têm português como língua materna. Esse cenário mostrou que escolas e famílias, em sua grande maioria, não estão capacitadas para essa tarefa de adotar estratégias diferenciadas para lidar com essa 
situação de multilinguismo nas famílias e nas escolas. Outro agravante, no qual as famílias e os profissionais da educação esbarram, é no desleixo, possivelmente advindo da inexperiência por parte dos governantes, em não saber como agir em tais situações de imigração recente e acabam incorrendo no mesmo erro já vivenciado desde o tempo da imigração no século XIX, que é de ofertar o ensino de português nas escolas, mas sem se preocupar com a capacitação de professores, tanto na português, quanto na variedade de imigração. Uma educação plurilinguística, que Broch (2014), Altenhofen e Broch (2011) e Kuchenbecker (2019) propõe para o ambiente escolar, considerando o ensino de línguas estrangeiras, poderia, com adaptações para a família e escola como um todo, ser uma postura a ser tomada, pois as noções de língua certa e errada, mais importante e menos importante, acaba colaborando com o preconceito linguístico, étnico, e racial, especialmente.

Kuchenbecker (2019), ao tratar da diversidade linguística nos domínios da escola, destaca que uma educação para o plurilinguismo não pode ser considerada somente para os contextos de escola com crianças falantes de mais de uma língua, mas sim para a escola em geral, como um direito do cidadão. Para a autora,

\footnotetext{
essa promoção passa, impreterivelmente, pela construção de uma competência plurilíngue e intercultural, desde os primeiros anos de escolaridade. É a partir desta concepção que se busca uma "educação plurilinguística". Trata-se de uma educação para a DL não só com o objetivo de incluir minorias, nem de um ensino isolado de LE, mas de promoção do plurilinguismo, por meio de abordagens de conscientização linguística e cultural. (KUCHENBECKER, 2019, p. 79-80)
}

O que podemos perceber são dois problemas iminentes, o primeiro, já exposto, é a falta de uma política linguística que valorize as variedades linguísticas alóctones e autóctones brasileiras e dê suporte tanto às novas variedades que estão entrando no país, quanto às variedades já existentes, evitando assim a sua extinção e a continuidade do mito de que só falamos português no Brasil (ALTENHOFEN, 2004). O outro problema condiz com a capacitação da mão de obra docente, assim como com a mão de obra dos profissionais da educação em geral, para que consigam lidar com situações de plurilinguismo valorizando, sem discriminação, cada uma das línguas do indivíduo.

Em se tratando dos benefícios que crianças bilíngues têm, professores entrevistados por Bernieri (2017) destacam a plasticidade do cérebro da criança, que aprende fazendo comparações entre línguas, noção esta já apresentada como benéfica por Gibbons e Ramirez (2004), que é um solo fértil para aquisição de mais de uma língua. Estudos como os de Grosjean (2010), King e Mackey (2007) e Romaine (1995) apontam grandes vantagens dos bilíngues em comparação aos monolíngues. Ser bilíngue deixou, há muito tempo, de ser algo que atrapalha, mas a falta de acesso à informação e, por que não dizer, a formação insuficiente dos professores em nosso país e, assim como a carga excessiva de trabalho dos docentes, faz com que não tenham tempo para se aprimorarem e, assim, o mito do monolinguismo se mantém vivo. 
A partir do relato abaixo de uma professora de F1, é possível perceber o sentimento de pesar da professora por não ter aproveitado a oportunidade para aprender uma segunda língua no âmbito familiar na infância:

\footnotetext{
Quando recebemos a visita da família do F1 em nossa escola, em nossa turma, logo cultivei admiração pela família, pela oportunidade que estavam proporcionando ao seu filho de aprender uma língua tão linda como o alemão desde bebê. Manifesto que acho lindo a língua alemã pois venho de família alemã, sendo que meu pai e meus avós paternos falam alemão ainda hoje entre eles. Porém, não aproveitei essa oportunidade para aprender uma segunda língua. (Registro no portfólio de F1 2014)
}

Fica evidente que a professora vê a importância de aprender uma segunda língua ainda na infância, mas o ponto em que queremos chegar é como esse profissional poderia contribuir para que crianças que não têm a português como materna, ou até mesmo crianças que ainda convivem com uma variedade de imigração, não percam a sua variedade linguística em detrimento da exigência da língua única no âmbito escolar. Percebemos que o profissional da educação ainda não está preparado para este novo cenário, pois uma questão é ser favorável ao ensino e aprendizagem de uma segunda língua, mas quando ela é uma variedade de imigração e todo o contexto de convívio social é a imersão numa comunidade de português, como fica a variedade linguística de imigração?

O que algumas comunidades escolares já fizeram foi implantar uma língua de imigração, como, por exemplo, o italiano e/ou o alemão padrão, mas será que essa língua, de fato, condiz com a variedade linguística falada na comunidade? Chega-se ao ponto de entender essa língua implantada na escola como uma outra LE e que implantar a língua oficial do país de origem no currículo escolar possivelmente irá promover a cultura daquela língua, mas não a variedade regional propriamente dita que, na maioria das vezes, é de base apenas oral. A diferença entre o falar uma variedade de imigração e o ensinar uma língua estrangeira em uma escola está no prestígio. Por isso, seria recomendado que a escola investisse, de forma consciente e planejada, numa educação plurilinguística, pois assim não se entraria no mérito da valoração da língua do outro e sim, da importância da manutenção de qualquer língua em uso na sociedade. A estratégia da escola pensar e debater com a sua comunidade escolar, qual LE pode ser implementada na escola, ao lado daquela prevista na BNCC, seria uma postura sensível à educação plurilinguística.

Conforme Calvet (2002, p. 145), é o Estado que teria o "poder e os meios de passar ao estágio do planejamento, de pôr em prática as escolhas lingüísticas (sic)", porém, política linguística envolve "um conjunto de escolhas conscientes referentes às relações entre língua(s) e vida social". Nesse sentido, compreendemos que uma política linguística precisa partir da necessidade da comunidade linguística, envolvendo as famílias, a escola em diálogo com o Estado.

A título de reflexão, podemos dizer que nosso sistema educacional está engessado numa cultura de inflexibilidade, na qual muitos professores estão focados em transmitir o conteúdo de suas disciplinas, mas não pensam na educação como um todo. Seria tão mais 
produtivo se parte das disciplinas de história, geografia, matemática, dentre outras, pudessem ser lecionadas em outra língua que não fosse o português. Assim, teríamos uma experiência mais plural na escola e, ao mesmo tempo, não deixaríamos de passar o conteúdo dessas disciplinas. Porém, temos aí outros limitadores; primeiro, seria necessário que tivéssemos profissionais para atender a tais necessidades e nossas licenciaturas, com raras exceções, não são dupla licenciatura e (um segundo limitador), precisaríamos rever os currículos dos cursos de licenciatura para formarem professores proficientes em LE e/ou sensíveis ao plurilinguismo já para os anos iniciais, no curso de Pedagogia, preconizando uma educação plurilinguística (BROCH, 2014; ALTENHOFEN; BROCH, 2011; KUCHENBECKER, 2019).

Enquanto nas escolas, principalmente nas públicas, o ensino é, desde 2019, quase que exclusivamente em língua inglesa, nas escolas privadas, ainda há a abertura para o ensino de outras línguas além do inglês, mas em nenhum dos contextos menciona-se pelo menos uma ponte entre a língua estrangeira com as variedades de imigração. O que acontece é uma marginalização das variedades de imigração tanto a recente quanto as variedades de imigração do século XIX. Podemos arriscar e dizer que essa marginalização é fruto do preconceito incutido na sociedade de que somente as variedades linguísticas de prestígio e internacionais modernas são "boas", e que as demais variedades, por serem oriundas de classes mais pobres, ou por serem a variedade dos avós ou variedade dos agricultores, na maioria ágrafas, não são "boas". Toda a língua, no momento em que cumpre com seu papel de comunicação entre interlocutores, deve ser tratada como língua, sem julgamentos e deve ser respeitada como tal. Em Bernieri (2017), registramos que os professores que vivem a realidade de alunos haitianos na escola, afirmam que deveria haver o ensino de francês na escola, a fim de que se pudesse ter uma maior interação de brasileiros com os imigrantes haitianos, através do conhecimento de sua língua e culturas.

Enfim, é necessário avançarmos nos estudos relacionados a uma educação plurilinguística e que isso não pode ter relação somente com as experiências que vivemos, ou seja, não podemos aguardar para avançarmos no sentido de adquirirmos conhecimento para trabalharmos com turmas de alunos multilíngues somente quando nos depararmos com essa realidade em sala de aula. Precisamos estar à frente e dar especial atenção à formação de nossos pedagogos e professores em geral.

\section{Considerações finais}

No Brasil, é possível investir numa educação plurilinguística precocemente no seio familiar, porém é preciso criar estratégias para dar conta de não perder a meta de vista. Há elementos facilitadores, que exemplificamos com a experiência que descrevemos anteriormente, porém também há elementos dificultadores que precisam de um envolvimento maior da sociedade em geral, especialmente da escola.

Ao retomarmos nossos objetivos, destacamos que i) ao apresentar o tipo 7 de aquisição bilíngue, de forma alguma, desconsideramos os tipos apresentados por Romaine (1995), no entanto, entendemos que é necessário pensarmos em um modelo que se adeque 
a nossa realidade no Oeste Catarinense, especialmente, pela compreensão das características do bilinguismo/plurilinguismo, que fazemos a partir de Mackey (1972). A situação linguística no Oeste Catarinense apresenta uma realidade complexa, com muitas línguas em contato diário (HORST; KRUG; FORNARA, 2017), no entanto, o preconceito presente na sociedade é muito marcado, no sentido da existência de somente uma forma correta de se falar português ou qualquer outra língua. Ainda em se tratando do tipo 7, que prevê que os filhos aprendem com os pais, no ambiente familiar, uma LE (alemão, no nosso caso) e, na sociedade, a língua oficial do país (português, na nossa realidade), não abrimos mão de "one person - one language"6 (ROMAINE, 1995), na nossa metodologia, uma vez que, na nossa compreensão, se a língua ficasse somente restrita ao ambiente da casa, a criação de um vínculo mais direto com a língua-alvo poderia ficar comprometida.

Também ii) descrevemos e analisamos a experiência de educação plurilinguística vivida com nossos dois filhos, ambos bilíngues/plurilíngues alemão-português, que passam a estudar em uma escola monolíngue em português e que residem em uma cidade na qual o alemão é muito pouco falado. Ficou evidente que a responsabilidade, num primeiro momento, frente a essa tomada de decisão, é dos pais e que é relevante fazer um planejamento daquilo que se pretende alcançar. Sem dúvida, ter algum conhecimento sobre plurilinguismo colabora muito para uma educação plurilinguística, por exemplo, para poder pensar em situações e formas de propiciar o máximo de input na língua-alvo para os envolvidos, mas também, para poder criar uma consciência sensível à diversidade linguística. A língua é determinante do êxito profissional, no estudo, na vida, no trabalho, do equilíbrio psicológico, ele é um elemento que agrega criatividade e visão de mundo. Também os profissionais da educação passam a ter um importante papel, pois precisam trabalhar com a família, no sentido de desconstruir o preconceito linguístico existente em relação ao status diferenciado das línguas. Ademais, é preciso criar na escola um ambiente educacional sensível ao plurilinguismo.

Por fim, procuramos iii) refletir sobre os desafios de uma educação plurilinguística que, em suma, exige muita dedicação e força de vontade tanto por parte dos professores quanto, e principalmente, por parte dos pais e dos filhos, pois todos os dias somos confrontados com a variedade majoritária, seja na rua, nos meios de comunicação ou no próprio lar. Por isso, é necessário desconstruir tanto o preconceito linguístico, fruto de educação centrada na crença da necessidade de uma homogeneidade linguística, quanto o mito de que crianças que aprendem mais de uma língua precocemente terão dificuldades na escola. Ademais, os professores que recebem em sua sala de aula alunos que não têm conhecimento de português, necessitam de muita sensibilidade e de uma educação plurilinguística (BROCH, 2014; ALTENHOFEN; BROCH, 2011; KUCHENBECKER, 2019), para que possam aprender a lidar com a situação. Vale lembrar que não necessariamente os professores precisam se tornar proficientes na língua das crianças, mas conhecer e saber lidar com tal situação de plurilinguismo. Também os pais devem estar cientes da responsabilidade e da importância de uma criação plurilíngue e assim, corroborar com a escola. Compreendemos que com os

\footnotetext{
${ }^{6}$ Uma pessoa - uma língua (ROMAINE, 1995).
} 
professores e os pais trabalhando juntos sem excluir ou dirimir uma ou outra variedade linguística fará com que a escola se torne mais sensível ao plurilinguismo, que, consequentemente, poderá levar a uma política educacional, tanto para línguas minoritárias, quanto de línguas chamadas "modernas" mais justa.

Esperamos que pais e professores se tornem, gradativamente, livres através do conhecimento e que assim colaborem a transformar a nossa sociedade, tornando-a mais consciente de que a diversidade linguística existe e que precisa ser respeitada e fomentada na sociedade. O plurilinguismo é a regra e não uma exceção e, por isso, é preciso investir numa educação plurilinguística na família e na escola.

\section{Referências}

ALTENHOFEN, C. V. O contato entre o português e as línguas de imigrantes no Brasil: o exemplo do Hunsrückisch. Palavra (PUCRJ), Rio de Janeiro, v. 11, p. 146-165, 2003.

ALTENHOFEN, C. V. Política lingüística, mitos e concepções lingüísticas em áreas bilíngües de imigrantes (alemães) no Sul do Brasil. Revista Internacional de Lingüística Iberoamericana, Frankfurt A. M., v. 3, p. 83-93, 2004.

ALTENHOFEN, C. V. Standard und Substandard bei den Hunsrückern in Brasilien: Variation und Dachsprachenwechsel des Deutschen im Kontakt mit dem Portugiesischen. In: LENZ, A. N. (Org.) German Abroad. Perspektiven der Variationslinguistik, Sprachkontakt- und Mehrsprachigkeitsforschung. Vienna: Vienna University Press, 2016 . p. 103-129. https://doi.org/10.14220/9783737005975.103

ALTENHOFEN, C. V; BROCH, I. K. Fundamentos para uma "pedagogia do plurilinguismo" baseada no modelo de conscientização linguística (language awareness). In: V ENCUENTRO INTERNACIONAL DE INVESTIGADORES DE POLÍTICAS LINGÜÍSTICAS, 2011, Montevideo. Anais... Montevideo, 2011. p. 15-24.

APPEL, R.; MUYSKEN, P. Bilingüismo y contacto de lenguas. Barcelona: Ariel Linguística, 1996. BAGNO, M. Preconceito Linguístico - o que é, como se faz. São Paulo: Edições Loyola, 1999.

BERNIERI, S. R. Crenças e atitudes linguísticas em relação a línguas minoritárias: alemão em São Carlos e italiano em Coronel Freitas. 2017. 187 f. Dissertação (Mestrado em Estudos Linguísticos) - Programa de Pós-Graduação em Estudos Linguísticos, Universidade Federal da Fronteira Sul, Chapecó, 2017.

BROCH, I. K. Ações de promoção da pluralidade linguística em contextos escolares. 2014. 267 f. Tese (Doutorado em Estudos da Linguagem) - Universidade Federal do Rio Grande do Sul: Porto Alegre, 2014.

CALVET, L.-J. Sociolingüística: uma introdução crítica. São Paulo: Parábola. 2002.

CAMPOS, C. M. A política da língua na era Vargas: a proibição do falar alemão e resistências no sul do Brasil. Campinas: Ed. da UNICAMP. 2006.

CHRIST, A. P. K.; PERES, E. P.; ROCHA, L. H. P. A história social dos contatos entre o Hunsrückisch e o Português em Domingos Martins - Espírito Santo. Web-Sociodialeto, Dourados, v. 10, p. p. 66-85, 2019. 
DALLEASTE, A. P.; BUSSE, S. Língua e Cultura Italiana em Matelândia/PR. Travessias, Cascavel, v. 10, p. 77-95, 2016.

GUY, G.; ZILLES, A. M. O ensino da língua materna: uma perspectiva sociolingüística. Revista Calidoscópio, São Leopoldo, v. 4, n. 1, p. 39-50, 2006.

GIBBONS, J.; RAMIREZ, E. Maintaining a minority language. A case study of hispanic teenagers. Clevedon, Bufalo, Toronto: Multilingual Matters LTD, 2004. https://doi.org/10.21832/9781853597428

GROSJEAN, F. Bilingual: live and reality. England: Harward University Press, 2010. https://doi.org/10.4159/9780674056459

HAMERS, J. F.; BLANC, M. H. A. Bilinguality and Bilingualism. 2. ed. Cambridge: Cambridge University Press, 2000.

HORST, A. Variação e contatos linguísticos do vestfaliano rio-grandense falado no Vale do Taquari. 2014. 232 f. Dissertação (Mestrado em Letras) - Universidade Federal do Rio Grande do Sul: Porto Alegre, 2014.

HORST, C.; BERTIOTTI, J. Multilinguismo na escola: crenças e atitudes linguísticas de professores de língua para/com imigrantes refugiados em escolas públicas de Chapecó. Muiraquitã, Acre, v. 7, p. 61-79, 2019. https://doi.org/10.29327/212070.7.2-6

HORST, C.; KRUG, M. J.; BERNIERI, S. R. Fatores (in)conscientes que influenciam uma ítalobrasileira a usar progressivamente o português em detrimento da variedade italiana. Caderno de Letras, Pelotas, v. 35, p. 195-208, 2019. https://doi.org/10.15210/cdl.v0i35.17409

HORST, C; KRUG, M. J.; FORNARA, A. E. Estratégias de manutenção e revitalização linguística no Oeste Catarinense. Organon, Porto Alegre, v. 32, n. 62, p. 1-16, 2017. https://doi.org/10.22456/2238-8915.72292

ILHA, S. E.; LARA, C. C.; CORDOBA, A. S. Consciência fonológica: coletânea de atividades orais para a sala de aula. Curitiba: Appris, 2017.

JUNGBLUT, R. Porto Novo: Um documentário Histórico. Porto Alegre: Ed. Letra Viva, 2011.

KING, K.; MACKEY, A. The bilingual Edge: Why, When and How to teach your child a second language. 1. ed. New York: 2007.

KRUG, M. J. Identidade e comportamento linguístico na percepção da comunidade plurilíngue alemão-italiano-português de Imigrante-RS. 2004. 132f. Dissertação (Mestrado em Linguagem no Contexto Social) - Universidade Federal do Rio Grande do Sul, Porto Alegre, 2004.

KRUG, M.; HORST, C. Atlas das Línguas em Contato na Fronteira - ALCF. In: SNICHELOTTO, C. A. R.; DA LUZ, N. M. S. (Org.) Livro comemorativo aos 5 anos do PPGEL. Chapecó: UFFS, (no prelo)

KRUG, M. J.; HORST, C.; WEPIK, F. F. Code-Switching na Fala de Polono-Brasileiros de Áurea/RS. Domínios de Lingu@gem, Uberlândia, v. 10, p. 1404-1423, 2016.

https://doi.org/10.14393/DL27-v10n4a2016-10

KRUG, M. J.; RUSCHEINSKY, E. W.; HORST, C. 'Uma vez': empréstimo do alemão no português falado em Itapiranga e São João do Oeste. Pandaemonium Germanicum, São Paulo, v. 22, p. 231-250, 2019. https://doi.org/10.11606/1982-88372237231 
KUCHENBECKER, I. Diversidad lingüística nos domínios da escola. In: IX ENCUENTRO INTERNACIONAL DE INVESTIGADORES DE POLÍTICAS LINGÜÍSTICAS, 2019, Rosario. Anais... Rosário: H. y A. Ediciones, 2019. p. 71-81.

LARA, C. C. Desvozeamento das plosivas bilabial, alveolar e velar do Português Brasileiro em contato com o Hunsrückisch. Revista do GELNE, João Pessoa, v. 17, p. 7-31, 2015.

MACKEY, W. F. The description of bilingualism. In: FISHMAN, J. A. (Org.). Reading in the sociology of language. 3. ed. The Hague: Mouton, 1972. p. 554-584. https://doi.org/10.1515/9783110805376.554

MORONI, A.; GOMES, J. A. O Português como Língua de Herança hoje e o trabalho da Associação de Pais de Brasileirinhos na Catalunha. REB - Revista de estúdios brasileños, Salamanca, v. 2, n. 2, p. 21-35, 2015. https://doi.org/10.14201/reb2015222135

MUYSKEN, P. Mixed codes. In: AUER, P.; LI, W. (Org.). Handbook of Multilingualism and Multilingual Communication. Berlin, Nova lorque: de Gruyter, 2007. 315-339.

ROMAINE, Suzanne. Bilingualism. 2. ed. Oxford: Basil Blackwell, 1995.

Recebido em: 20/04/2020.

Aceito em: 20/10/2020. 